\title{
A new methodology for approaching motorcycle riders' behavior at curved road sections
}

\author{
P. V. Lemonakis • N. E. Eliou • T. Karakasidis • \\ G. Botzoris
}

Received: 11 February 2013 / Accepted: 8 January 2014 /Published online: 6 February 2014

(C) The Author(s) 2014. This article is published with open access at Springerlink.com

\begin{abstract}
Objective The present paper focuses on the investigation of motorcycle riders' behavior at curved road sections by introducing a new methodology based on global positioning system (GPS) technology. In the frame of the research, the determination of the optimum regression curve between the curve radius' and the corresponding velocities, was investigated.

Design Within the context of the paper field measurements were conducted, with the use of appropriate velocity recording equipment in order to confirm the efficiency of the proposed methodology. The measurements were conducted taking into account various factors that potentially influence riders' behavior such as the different light conditions, the difference on riding experience level, the familiarity of the riders with the routes, the presence of pillion and the different road environments, such as width/condition of the road pavement, roadside land use, right/left hand curves etc.

Setting The experimental environment that served the needs of the experiment was mountain Pelion in Magnesia region in Greece and was based upon four primary conditions: the location, the type of the road, the weather conditions and finally, the time and date that the experiment would be conducted.

Participants The validation of the proposed methodology was performed by recruiting two motorcyclists. Their selection was based on demographic, psychometric and experience criteria.
\end{abstract}

\author{
P. V. Lemonakis $(\bowtie) \cdot$ N. E. Eliou $\cdot$ T. Karakasidis \\ Department of Civil Engineering, University of Thessaly, Pedion \\ Areos, 38334 Volos, Greece \\ e-mail: plemonak@uth.gr \\ N. E. Eliou \\ e-mail: neliou@uth.gr \\ T. Karakasidis \\ e-mail: thkarak@civ.uth.gr \\ G. Botzoris \\ Department of Civil Engineering, Democritus Thrace University, \\ Vas. Sofias 12, 67100 Xanthi, Greece \\ e-mail: gbotzori@civil.duth.gr
}

Results The research showed among others, that the regression curves could be used as a curve classification mean. Moreover, a significant variation was detected on the riders' behavior when carrying a pillion related to their experience levels.

Keywords Motorcyclists' behavior · Riders' behavior . Ordinary least square method · Radius curve $\cdot$ Operating speed $\cdot$ Speed equations $\cdot$ GPS

\section{Introduction}

Numerous studies have been carried out during the last decades in the field of road safety in order to predict the relationship between driver behavior and road features (especially on horizontal curves). Many of these studies focus on creating analytical models expressing driver behavior in relation to the characteristics of the roads [1-4]. In these models, driver behavior is expressed by the operating speed $\left(\mathrm{V}_{85}\right.$, that represents the 85th-percentile speed), while the road characteristics are generally represented by the curvature change rate of the single curve or the horizontal curve radius, since it has been estimated that the magnitude of the radius of the horizontal curves is the most considerable factor that determines operational speed [5]. Nevertheless, the true effect of each individual geometric variable (e.g. Curve radius, length of the curve, deflection angle and superelevation) is still not known precisely in quantitative terms [6]

As stated in a recent study [7], most models developed to date focus on passenger car speeds. However, the speed behavior of motorcycles was studied by Perco [8] who evaluated the possibility to develop a motorcycle operating speed prediction model analyzing the relationships between the motorcycle operating speed and the passenger cars operating speed. Both motorcycle and vehicle speeds were collected using a Light Detection and Ranging (Lidar) gun while graphic as well as statistical analysis followed the measurements. 
The outcome of this research was the development of the following equation:

$$
\mathrm{V}_{85 \mathrm{PTW}}=1.162 \times \mathrm{V}_{85 \mathrm{PC}} \quad \mathrm{R}^{2}=0.94
$$

Where:

$$
\begin{array}{ll}
\mathrm{V}_{85 \text { PTW }} & \begin{array}{l}
\text { is the } 85 \text { th percentile speed on tangent of PTWs } \\
(\mathrm{km} / \mathrm{h})
\end{array} \\
\mathrm{V}_{85 \mathrm{PC}} & \begin{array}{l}
\text { is the } 85 \text { th percentile speed on tangent of passenger } \\
\text { cars }(\mathrm{km} / \mathrm{h})
\end{array} \\
\mathrm{R}^{2} & \text { is the coefficient of determination. }
\end{array}
$$

The objective in another study by Faezi et al [9] was to develop a speed prediction equation on horizontal curves using the geometric characteristics of the curves at 11 sites in exclusive motorcycle lane. To achieve this objective, the speeds of motorcyclists were measured in exclusive motorcycle lanes in Malaysia using two devices; a portable laser speed detector and a digital video camera. The authors of this study using linear regression procedure in order to identify the best fit combinations of the independent variables, developed the following model:

$\mathrm{V}_{85 \text { Curve }}=19.357 \mathrm{~W}-0.394 \Delta+0.654 \mathrm{~T}$

Where:

$\begin{array}{ll}\mathrm{V}_{85} & \text { is the 85th percentile motorcycle speed on } \\ \text { Curve } & \text { horizontal curves } \\ \mathrm{W} & \text { is the total lane width } \\ \Delta & \text { is the deflection angle } \\ \mathrm{T} & \text { is the length of tangent. }\end{array}$

No other study relevant to motorcycle speed prediction equations has been carried out apart from the two aforementioned ones, at least to our knowledge. Therefore the impact of the different light conditions, the different experience level, the familiarity with the road and the different road environment to drivers' behavior expressed in operating speed changes can only be observed in passenger cars studies.

The differences in driving behaviors when passenger car drivers deal with right-hand (RH) and left-hand (LH) curves, have been examined by several researchers. More specifically, the results of these investigations, as discussed in a study by Fildes [10], showed that the drivers use different optical cues in $\mathrm{RH}$ and $\mathrm{LH}$ curves, have higher driving performance in $\mathrm{RH}$ curves and tolerate higher deviations from design course in $\mathrm{RH}$ in comparison to LH curves with similar features.

The fact that drivers respond in a different way to RH and LH curves also derives from a study by Othman et al [11], in which it is clearly indicated that the curve direction should be substantially studied in the designing or redesigning of the curves. It actually became apparent that the drivers and the vehicles are influenced by different infrastructure elements according to the curve direction.

It is known from the law of mechanics that the force resolution for resolving the forces acting on a vehicle traversing a curve, leads to the following formula [12]:

$\mathrm{e}+\mathrm{f}=\frac{\mathrm{U}^{2}}{\mathrm{R} * \mathrm{~g}}$

\section{Where:}

e is the superelevation

$\mathrm{f}$ is the side friction factor

$\mathrm{R}$ is the radius of curvature

$\mathrm{U}$ is the speed of the vehicle.

Equation 3 is based on the force balance for a point mass on a superelevated surface travelling at constant speed along a circular arc. However, when using Eq. 3, one of the basic problems encountered, as it was mentioned before, is the hypothesis that the radius is constant. That of course is because vehicles change their lane placement and trajectory and as a result the driven path might vary considerably from the curve radius. This was confirmed by many researchers, as discussed in a study by Bennett [13], who noticed that the trajectory can be considerably different from the design course. More specifically in curves with radius less than $150 \mathrm{~m}$, drivers tended to increase the radius of their path, from $0.6 \mathrm{~m}$ to $0.9 \mathrm{~m}$, in lateral position when driving inside the curve. It should be noted that since the curve radius and the path radius vary, the calculation of the side friction factor constitute a complex problem, as shown in a study by Wong and Nicholson [6] who suggested that the path instead of the design radius should be taken into account.

The approach to riders' behavior at curved road sections at the present study, has been achieved by proposing a new methodology of measuring speeds based on GPS technology which preceded the conduction of field measurements in order to confirm its efficiency. The field measurements were designed taking into account various factors that potentially influence the riders' behavior such as the different light conditions, the difference on the riding experience level, the familiarity of the riders with the routes, the presence of pillion and the different road environments, such as width/condition of the road pavement, roadside land use, right/left hand curves etc aiming to enhance riding safety.

\subsection{Planning of experimental procedures}

\subsubsection{Recruitment}

Initially, three basic parameters had to be defined with regards to the participants' selection that would execute the field 
measurements; demographic criteria, riding experience and psychometric aspects of the riders [14].

The choice of the participants' gender was based on preceding researches which have shown that males are overrepresented both in car and motorcycle accidents [15, 16], but also in the riding population even though they do not necessarily demonstrate riskier behaviors. Moreover, males constitute the typical rider gender and they can be recruited easier than the female ones.

Experience is also a significant factor that determines the level of risk taking behavior among riders. In most of the cases, there is a correlation between riding experience and age, since young riders are more inexperienced in comparison to the older ones who are more experienced. In order to reduce the probability of accident occurrence during the experiment, young and older riders were excluded, due to their high risk rates. Consequently, all participants had to have an actual riding experience of at least 5 years and should not be older than 50 years old. Aiming also to the latter target, the sample of riders was biased towards riders with limited accident records. Furthermore, since one of the main objectives of the present research was to determine how the riding experience affects riding behavior, efforts were made in order to match the overall participants' features apart from their riding experience, which was selected to be considerably different.

Another issue that had to be dealt with was that the riders had to achieve a certain level of familiarity with the instrumented motorcycle. For that reason, prior to the execution of the field measurements, the riders were asked to ride the experimental motorcycle until they felt confident with its operation. It should also be noted that the demands for adequate handling were relatively increased due to the size and weight of the instrumented motorcycle.

Taking under consideration the afore-mentioned, two male riders belonging at the same age group were selected to carry out the field measurements. None of them revealed any obvious reason of impaired riding ability while their riding experience levels were totally different. Moreover, they had common stay of residence, adjacent to the routes where the experiment was conducted and therefore, they both had similar familiarity with the experimental environment.

\subsection{Recording device}

Many researchers have obtained speed data, using in most cases, a radar gun [17, 18] as well as speed detectors [9]. Both methods can introduce errors such as measuring errors or can influence drivers' behavior who might perceive the speed record equipment and hence, adjust their speeds to the legal speed limits of the sections studied [7]. Therefore in order to overcome the shortcomings of the speed recording equipment that has been used so far we established a new speed record method which was based on the usage of GPS data logger.
Data loggers can record GPS, video and vehicle data and are ideally suited to motorsport due to their small weight, size and increased accuracy. Moreover without fitting any other sensors, the measure of speed, track position, distance, lap time, lateral acceleration, longitudinal acceleration and height is feasible. Recording of such parameters can be particularly useful especially in cases where driving behavior is not approached exclusively in speed terms. In addition, by using a single record system it is possible to investigate the behavior of the riders in multiple curves, since the various equipment are attached onto the vehicle instead of the road.

In this view the equipment that was used to record the relevant with the riding performance parameters, such as position and velocity was the Video Vbox from Racelogic Company. The Video Vbox combines a powerful GPS data logger with a high quality solid-state video recorder. In order to capture the video file, it is equipped with two cameras and two microphones whilst records the following parameters as standard along with the video file: satellites, time, latitude, longitude, velocity, heading, height and vertical velocity.

The videos, as well as the data files are saved onto an SD card. The logging rate is ten samples per second, which was considered as adequate enough to cover the needs of the experiment. As an example, an 8-gigabyte high capacity SD card, logging video on the highest quality setting was able to $\log$ approximately $160 \mathrm{~min}$ of video. Apparently, this is an approximation, as the size of the recorded video depended on what was being recorded. The motion, color and complexity of the subject matter affected the size of the video file created. It should also be mentioned that the size of the data file was particularly small, in comparison to the size of the video file. The recorded data were downloaded daily right after the execution of the experiment from the flash memory to an external High Capacity HD that was given to the riders.

The type of the recorded video file was MPEG-4 while the data logger was set to capture it only when the motorcycle was moving by using $2 \times \mathrm{AV}$ cameras with integrated $12 \mathrm{~V}$ power supplies and $2 \times$ external microphones (the output sound was MP2 encoded video stream). The quality of the 24 bit color captured video file was either DVD $720 \times 576$ at 25 frames/sec or DVD $720 \times 480$ at 30 frames/sec.

Finally the accuracies of the recording device was $\pm 0,2 \mathrm{Km} / \mathrm{h}$ for the velocity values, $\pm 0,05 \%$ for the distance values, $\pm 5 \mathrm{~m}$ for the position values, $\pm 10 \mathrm{~m}$ for the height values and $\pm 0,5 \%$ for the lateral and longitudinal acceleration.

\subsection{Instrumented motorcycle}

The instrumented bike that was used to carry out the field measurements was a BMW F650 (Fig. 1).

It is an on/off motorcycle, which is widespread on rural Greek roads, especially because of its ability to provide sufficient transport on asphalt, as well as on soil material surfaces. 


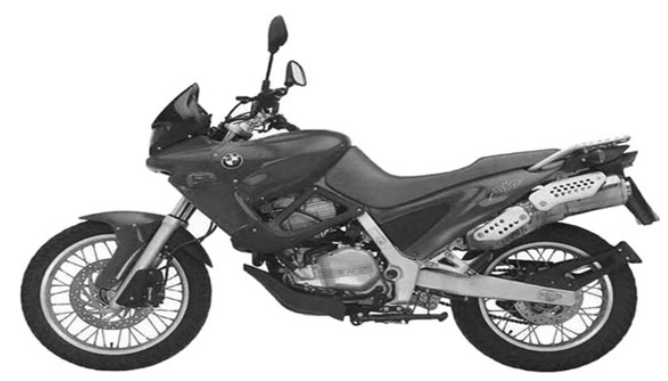

Fig. 1 Instrumented motorcycle

The displacement of the 4-stroke single cylinder engine is $652 \mathrm{ccm}$ with peak output of $48 \mathrm{hp}$ at 6,500 rpm. Among other specifications, the instrumented motorcycle has top speed at $160 \mathrm{~km} / \mathrm{h}$, it accelerates from 0 to $100 \mathrm{~km} / \mathrm{h}$ at $5.2 \mathrm{~s}$, it is equipped with a 5 -speed gearbox, its seat height and weight is $82 \mathrm{~cm}$ and $199 \mathrm{~kg}$ respectively while both front and rear brakes consist of single disc.

\subsection{Experimental environment}

The selection of the experimental environment had to be based upon four primary conditions: the location, the type of the road, the weather conditions and finally, the time and date that the experiment would be conducted. All of these four conditions had to be common for both riders in order to record comparable data.

The location of the experiment should ensure on one hand the constant function of the recording device, and on the other hand the presence of a large number of curved sections. Moreover, the traffic volumes should be particularly limited during the experiment in order to achieve unaffected riding behavior. Finally, for purely practical purposes, the experimental environment was sought close to the participants' place of residence. Taking into account the above-mentioned, the road network that would serve the needs of the research and meet the requirements of the experiment was mountain Pelion, in Magnesia.

The road network of Pelion consists exclusively of intensive curved rural roads, which vary depending on its geometrical characteristics, the presence of vertical/horizontal signage and the pavement condition. The traffic volumes are very limited during the autumn and winter months. Additionally, after the conduction of several trial tests it was verified that the record device was working properly.

In a more detailed investigation, the following road sections were determined as appropriate to carry out the field measurements:

1rd road section: Part of rural road Afyssos - Afetai $\left(39^{\circ} 16^{\prime} 30.24^{\prime \prime} \mathrm{B}, 23^{\circ} 10^{\prime} 1.12^{\prime \prime} \mathrm{A}\right.$ to $39^{\circ} 16^{\prime} 53.69^{\prime \prime} \mathrm{B}$, $\left.23^{\circ} 10^{\prime} 41.10^{\prime \prime} \mathrm{A}\right)$. Length: approximately $2.300 \mathrm{~m}$

2st road section: Part of rural road Milina - Lafkos $\left(39^{\circ} 10^{\prime} 6.58^{\prime \prime} \mathrm{B}, 23^{\circ} 13^{\prime} 43.97^{\prime \prime} \mathrm{A}\right.$ to $39^{\circ} 10^{\prime} 0.43^{\prime \prime} \mathrm{B}, 23^{\circ} 14^{\prime}$ 21.94"A). Length: approximately $2.300 \mathrm{~m}$ 3nd road section: Part of rural road Neohori - Kalamaki $\left(39^{\circ} 18^{\prime} 43.98^{\prime \prime} \mathrm{B}, 23^{\circ} 12^{\prime} 49.28^{\prime \prime} \mathrm{A}\right.$ to $39^{\circ} 19^{\prime} 23.41^{\prime \prime} \mathrm{B}$ $\left.23^{\circ} 11^{\prime} 45.51^{\prime \prime} \mathrm{A}\right)$. Length: approximately $2.550 \mathrm{~m}$

The evaluation as well as the location of the experimental road sections are indicated in Table 1 and Fig. 2 respectively.

Regarding the weather conditions and in order to restrict the parameters that affect the riding behavior of the participants, both riders instructed to cease the measurements when the pavement was even slightly wet. The natural lighting level should be constant and hence, during cloudy or foggy days the measurements were ceased as well. In general, the instructions that were given to the riders, forbidden the execution of the experiment in case any environmental or traffic conditions might divert their regular riding behavior. It is also noted that the unimpeded approach to the curves ensured by succeeding null traffic volumes. For that purpose the measurements were conducted when the road was free from the presence of other road users.

Aiming at the investigation of the correlation between natural lighting and riding behavior, two different time periods were set for the execution of the experiment. The first one was set between 09:00 and 16:00 (constant natural lighting during autumn-daytime measurements) and the second one between 21:00 and 01:00 (nighttime measurements). Apparently, apart from the lighting conditions all the other environmental and weather conditions were equivalent for both time periods.

Apart from the investigation of the correlation between lighting conditions and riding behavior, another aim of the present research was the inquiry of the contribution of the familiarity with a road to the riding behavior. For that purpose the participants were asked to ride each one of the routes six times during daytime and six times during nighttime. Finally, after the completion of the twelve afore-mentioned measurements, the riders were asked to repeat each route once more with the presence of a pillion in order to investigate how this condition influences their riding behavior since the presence of a pillion affects firstly the total weight of the system rider/ motorcycle and secondly it increases the sense of responsibility of the rider for the pillion's safety. In total, both riders conducted 78 measurements as analytically shown in Table 2.

\subsection{Data processing method}

The data analysis was based on three program packages; Vbox Tools v2.2.2 b042 of Racelogic (http://www.racelogic.co.uk/), Excel 2007 of Microsoft (http://www.microsoft.com) and Autocad 2009 of Autodesk (http://www.autodesk.com). The original data files recorded at the SD card (extension *.vbo) opened using Vbox Tools and then were simply converted to comma delimited files (extension *.csv). Each *.csv file corresponded to a specific measurement and contained three columns; velocity, coordinate $\mathrm{x}$ and coordinate $\mathrm{y}$. It is 
Table 1 Evaluation of the experimental routes

\begin{tabular}{|c|c|c|c|}
\hline \multirow[b]{2}{*}{ Attribute } & \multicolumn{3}{|l|}{ Road section } \\
\hline & $A-A^{a}$ & $M-L^{b}$ & $\mathrm{~N}-\mathrm{K}^{\mathrm{c}}$ \\
\hline Curve radius range $\left(\mathrm{R}_{\min }-\mathrm{R}_{\max }\right)$ & $11 \mathrm{~m}-315 \mathrm{~m}$ & $24 \mathrm{~m}-157 \mathrm{~m}$ & $49 \mathrm{~m}-222 \mathrm{~m}$ \\
\hline Total pavement width & 2.60/direction & 3.00/direction & 4.10/direction \\
\hline Horizontal signage & Absent & $\begin{array}{l}\text { Continuous single line on the centerline and } \\
\text { the boundaries of the road }\end{array}$ & Yes \\
\hline Vertical signage & Absent & Partially (three danger signs) & Yes \\
\hline Guard rails & Absent & Absent & Yes \\
\hline Pavement condition & $\begin{array}{l}\text { Extensive surfaces with cracks, } \\
\text { grooves and subsidence }\end{array}$ & $\begin{array}{l}\text { Several spots with transverse and longitudinal cracks, } \\
\text { grooves and layering of bituminous seal }\end{array}$ & Excellent \\
\hline Artificial lighting & Absent & Absent & Absent \\
\hline Evaluation & Poor & Satisfactory & Excellent \\
\hline
\end{tabular}

${ }^{\text {a }}$ Afyssos - Afetai

${ }^{\mathrm{b}}$ Milina - Lafkos

${ }^{\mathrm{c}}$ Neohori - Kalamaki

reminded that these values were recorded at a sampling rate of $10 \mathrm{~Hz}$.

Since coordinates $\mathrm{x}$ and $\mathrm{y}$ were known the design of the trajectory of each measurement was feasible in Autocad using the appropriate lisp (functional language). Moreover, a number was assigned in each pair of $\mathrm{x}$ and $\mathrm{y}$ coordinates in ascending order, starting from number 1 for the first recording. Apparently, the last number varies among the measurements since it derives from the total time that each measurement completed.

Apart from the design of the trajectory of each measurement, it was also drawn a representative rendering of the line of each route and its geometrical characteristics and especially the edge of the traveled way (reference arc) that none of the riders encroached in each curve. The radius that refers to each reference arc was then used to the analysis that followed (Fig. 3). Hence the results and conclusions of the present research were not based upon the geometrical radius of the curves and thus cannot be used as evaluation criteria of design consistency.

The knowledge of the beginning and end of each curve (different numbers for each measurement as implied below) led to the determination of the beginning and end number for each curve and measurement. Thereafter by simply averaging the velocities within the beginning and end number we calculated the mean velocity (apparently for each curve and measurement). It is noted that the velocity of each measurement at the beginning and end of each curve was calculated with linear regression of the values right before and right after the curve implying that the trajectory and hence the variation of the velocity between two consecutive points, is linear.

By this means the calculation of the mean velocities in each curve for each one of the 78 different measurements was possible. More specifically, 50 curves were determined for

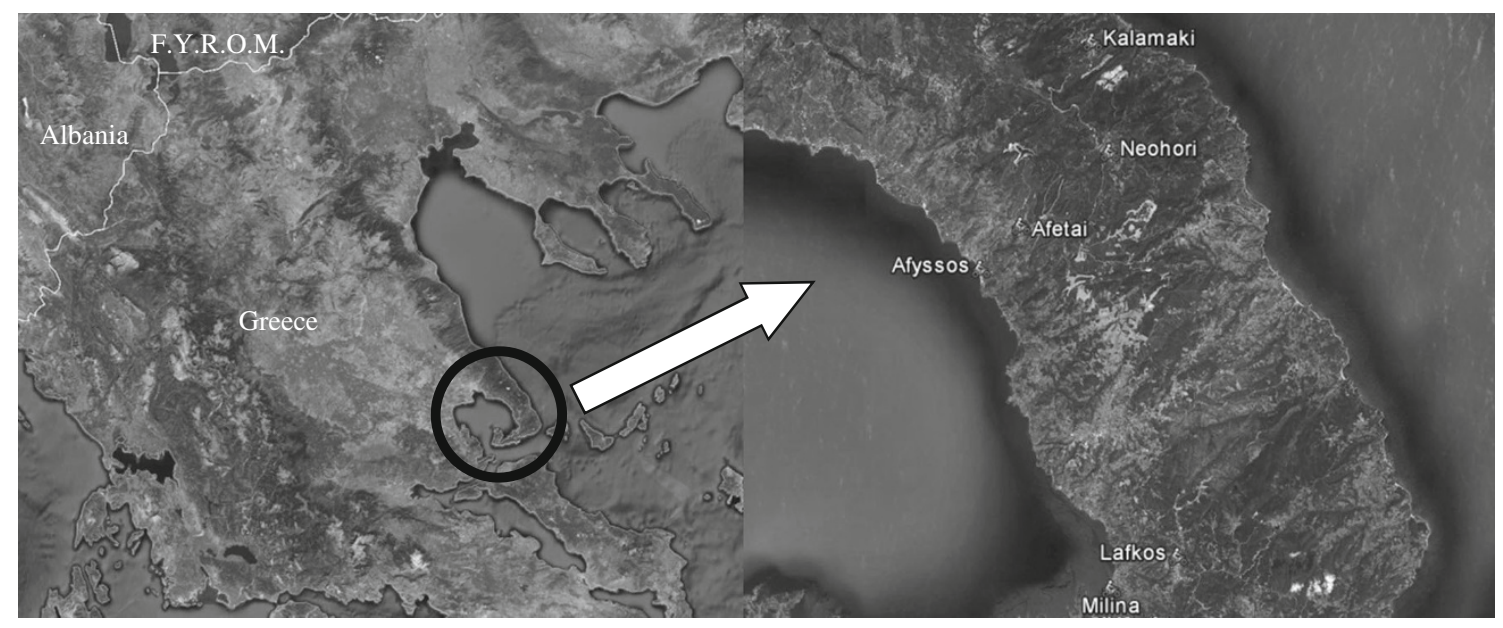

Fig. 2 Experimental road sections 
Table 2 Amount of measurements

\begin{tabular}{lllll}
\hline Condition & $\begin{array}{l}\text { Number of } \\
\text { routes }\end{array}$ & $\begin{array}{l}\text { Number of } \\
\text { repetitions }\end{array}$ & $\begin{array}{l}\text { Number of } \\
\text { riders }\end{array}$ & Total \\
\hline Daytime & 3 & 6 & 2 & 36 \\
Nighttime & 3 & 6 & 2 & 36 \\
Pillion & 3 & 1 & 2 & 6 \\
Total amount of measurements & & 78 \\
\hline
\end{tabular}

further analysis; 20 curves located at route Afyssos - Afetai ( 9 curves were right hand while 14 curves had radius $R<100 \mathrm{~m}$ ), 20 curves located at route Milina - Lafkos (10 curves were right hand while 13 curves had radius $R<100 \mathrm{~m}$ ) and 10 curves located at route Neohori - Kalamaki ( 6 curves were right hand while 3 curves had radius $R<100 \mathrm{~m}$ ) accounting a sample size of 1,300 mean velocities, as shown in Table 3.

The next step of the data processing method was to determine the method to calculate the equations that correlate the recorded velocities with the corresponding radiuses of the horizontal curves as defined above. Previous research has shown that linear regression can be used to predict operating speeds on circular curves. The results of researches as discussed in a study conducted by Abdul-Mawjoud and Sofia [19] showed that the 85th percentile speeds on horizontal curves - the dependent variable_can be predicted using combinations of independent variables such as curve radius, length of the curve, deflection angle, and superelevation. Apart from the afore-mentioned studies, it was evident that the ordinary least square (OLS) regression was the most widespread model type among the various researchers that has been used in order to develop comprehensive speed prediction equations/models [7] and for that reason it was selected against other model types.

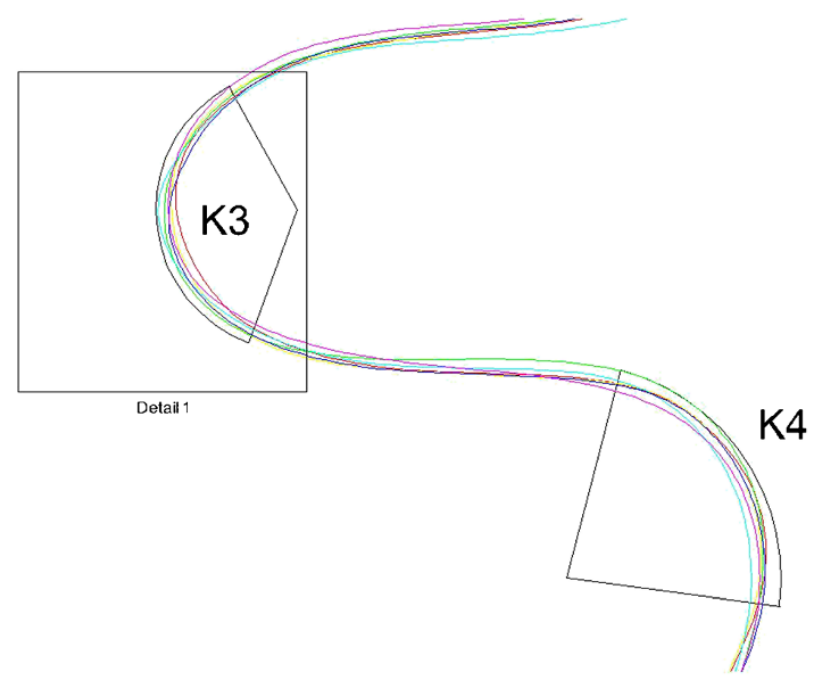

\section{Results}

The calculation of the mean velocities followed by the implementation of the ordinary least square regression method in order to determine the optimum regression curve between radius and velocity that fitted better the distribution of the collected data.

Equation 3 presented above, can be rewritten as:

$$
\mathrm{U}=\sqrt{(\mathrm{e}+\mathrm{f}) \mathrm{Rg}}
$$

Hence, the maximum speed of a vehicle traversing a curve in order not to invert or skid is given by:

$\mathrm{U}=\mathrm{a} \sqrt{\mathrm{R}}$

Where:

$\mathrm{U}$ is the velocity of the vehicle

$\mathrm{R}$ is the radius of the curve

a is a coefficient depending on the center of gravity of the vehicle, the dimensions of the vehicle, the side friction factor and the superelevation angle of the curve.

Therefore it is essential for a driver to be aware of the fact that the centrifugal force $\mathrm{F}$ is proportional to the speed square and inversely proportional to the radius of the curve and hence side-slip phenomena might not appear when the rider accomplishes to increase the radius of his trajectory. This could be done when the riders cut the corner in such way that they exploit the largest part of the available pavement edges (Fig. 4).

Accordingly, the rider traverses curved tracks with radius dissimilar than the radius of the curves at the center line of the road (geometric radius). Thus, the rider moves within $\mathrm{LH}$ curves between $\mathrm{R}$ and $\mathrm{R}+\mathrm{d}$ (where $\mathrm{d}$ is the width of the lane) whereas in $\mathrm{RH}$ curves between $\mathrm{R}$ and $\mathrm{R}-\mathrm{d}$, assuming

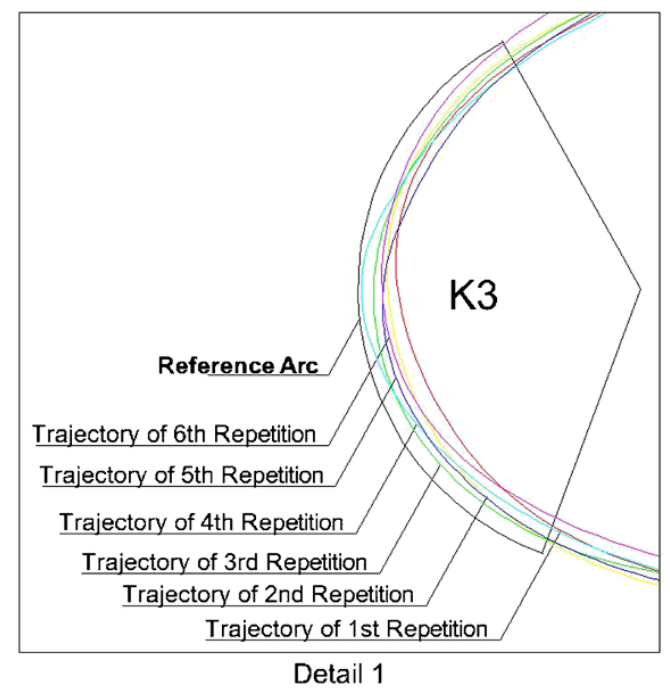

Fig. 3 Construction of reference arc 
Table 3 Sample size

\begin{tabular}{|c|c|c|c|c|c|c|c|c|c|c|c|c|c|}
\hline & \multicolumn{6}{|c|}{ Rider 1} & \multicolumn{6}{|c|}{ Rider 2} & Total \\
\hline \multicolumn{14}{|c|}{ Afyssos - Afetai } \\
\hline Repetition & 1 & 2 & 3 & 4 & 5 & 6 & 1 & 2 & 3 & 4 & 5 & 6 & \\
\hline Daytime & 20 & 20 & 20 & 20 & 20 & 20 & 20 & 20 & 20 & 20 & 20 & 20 & 240 \\
\hline Nighttime & 20 & 20 & 20 & 20 & 20 & 20 & 20 & 20 & 20 & 20 & 20 & 20 & 240 \\
\hline Pillion & 20 & & & & & & 20 & & & & & & 40 \\
\hline \multicolumn{14}{|c|}{ Milina - Lafkos } \\
\hline Repetition & 1 & 2 & 3 & 4 & 5 & 6 & 1 & 2 & 3 & 4 & 5 & 6 & 240 \\
\hline Daytime & 20 & 20 & 20 & 20 & 20 & 20 & 20 & 20 & 20 & 20 & 20 & 20 & 240 \\
\hline Nighttime & 20 & 20 & 20 & 20 & 20 & 20 & 20 & 20 & 20 & 20 & 20 & 20 & 40 \\
\hline Pillion & 20 & & & & & & 20 & & & & & & \\
\hline \multicolumn{14}{|c|}{ Neohori - Kalamaki } \\
\hline Repetition & 1 & 2 & 3 & 4 & 5 & 6 & 1 & 2 & 3 & 4 & 5 & 6 & \\
\hline Daytime & 10 & 10 & 10 & 10 & 10 & 10 & 10 & 10 & 10 & 10 & 10 & 10 & 120 \\
\hline Nighttime & 20 & 10 & 10 & 10 & 10 & 10 & 10 & 10 & 10 & 10 & 10 & 10 & 120 \\
\hline Pillion & 10 & & & & & & 10 & & & & & & 20 \\
\hline Grand total & & & & & & & & & & & & & 1,300 \\
\hline
\end{tabular}

apparently that he remains at his lane throughout his movement within the curve. Therefore the rider can achieve greater speeds in LH curves than in RH curves (since centrifugal force $\mathrm{F}$ is constant and hence greater speed presuppose greater radius), given the fact that $\mathrm{LH}$ curves postulate greater radiuses. In this context, since the graphs represent speed against geometric radius, higher speeds are shifted to smaller radiuses in LH curves. This remark is particularly important in curves with small radiuses.

It is worth noting that Eq. 4 assumes the execution of Uniform Circular Motion by the rider, which is not precisely applied due to the different speeds as well as to the different consecutive radiuses he traverses within the curve, resulting an error. Therefore Eq. 4 can be rewritten in a more general form as:

$\mathrm{U}=\mathrm{aR}^{\mathrm{b}}$

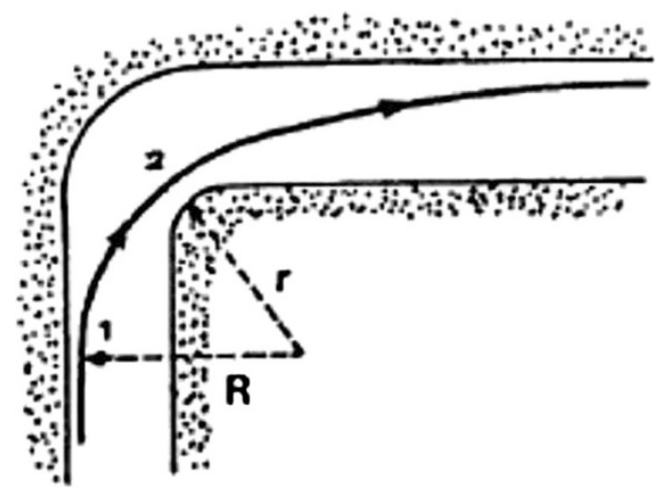

Fig. 4 Trajectory of changing radius
Equation 5 compares favorably with Eq. 4 because on one hand it does not involve mandatory Uniform Circular Motion (b not compulsorily equal to 0.50 ) on the other hand exponent $b$ could be used as a criterion whether the motion of the rider approaches the uniform circular (the more $b$ tends to 0.50 the more motion approaches uniform circular). Taking into consideration the afore-mentioned idea it was decided to implement ordinary least square regression to Eq. 5 that led to the calculation of the trend lines, the corresponding errors of coefficients $\mathrm{a}, \mathrm{b}$ and the coefficient of determination $\mathrm{R}^{2}$ for 64 different driving conditions. These conditions were oriented to investigate the impact of the different light conditions, the difference on the experience level, the familiarity of the riders with the routes, the presence of a pillion and the different road environments (e.g. LH and RH curves) to the participants riding behavior. The comparison of the various driving conditions performed by evaluating the behavior of the corresponding exponent $\mathrm{b}$ and coefficients $\mathrm{a}$.

A thorough examination of RH curves (cases 57-64 of Table 4 at appendix) showed that exponents $b$ tend more to 0.50 and thus the rider's movement approaches more a uniform circular motion (and hence the rider does not change his radius very much and he moves with lower speeds). Conversely in LH curves, exponent b presents lower values because the rider can divert more from uniform circular motion by changing his speed and radius. This behavior might imply that in RH curves the riders probably move closer to the limit value of 0.50 (Eq. 4) than in LH curves. Moreover it is interesting to note that the difference is also depicted in the coefficient a of Eq. 5. Thus it is obvious that in LH curves the coefficients a are greater than in $\mathrm{RH}$ curves. In general for 
curves with radiuses above $100 \mathrm{~m}$ and independently of the light conditions, both riders traverse RH curves with higher speeds than LH curves (Figs. 5, 6, 7 and 8). This conclusion reverses for curves with radiuses below $100 \mathrm{~m}$, phenomenon that should be further investigated in the future.

An additional conclusion that came up is that in the routes with better geometric characteristics (according to Table 1) exponents $b$ reduce while coefficients a increase. Hence in these routes the riders have greater range of curvature selection.

The evaluation of the calculated equations presented in Appendix A led to the conclusion that regression curves between speed and radius could be used as a classification tool of the road curves. Exponents b approaching 0.50 would indicate that the rider moves closer to the limit speed and hence such curves gather poor geometric characteristics. Similarly, the behavior of coefficient a is also related to the quality of the road. More specifically, comparing resembling experimental conditions (e.g. behavior of experienced rider at nighttime), the value of coefficient a increases when the quality of the road-according to Table 1 - increases (cases 12, 24 and 36 respectively of Table 4 at appendix).

Moreover the mean velocity of the experienced rider at the repetitions with the presence of the pillion is considerably higher than the corresponding velocity of the inexperienced rider (Fig. 9) implying that the experienced rider perceives more efficiently the benefit of the increased weight of the system motorcycle - rider - pillion which is accompanied by the increase of the side friction and therefore it permits higher speeds. This is clearly reflected in Fig. 10 which shows the mean speed of the experienced rider for the various driving conditions where the highest speed is observed at the repetitions with the presence of the pillion.

On the contrary, the afore-mentioned benefit is limited perceived by the inexperienced rider probably due to the sense of responsibility towards the pillion (Fig. 11).

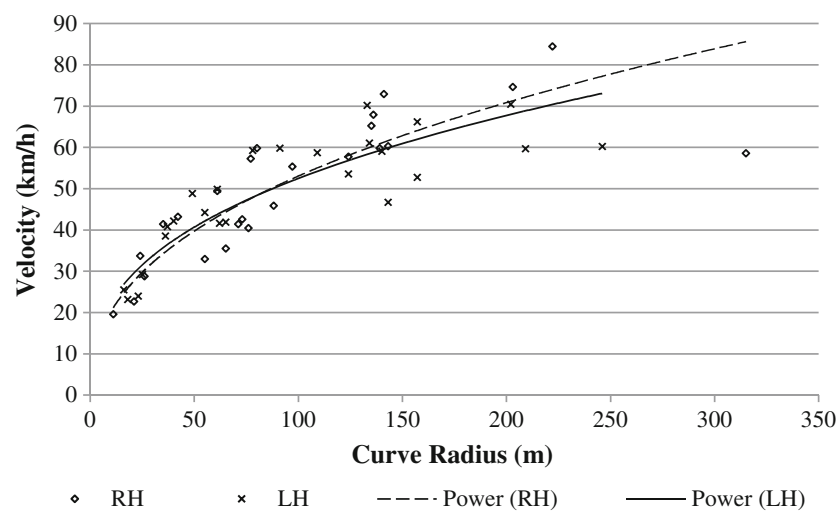

Fig. 5 Velocity Vs curve radius in all routes by inexperienced rider in Right Hand (RH) and Left Hand (LH) curves during daylight

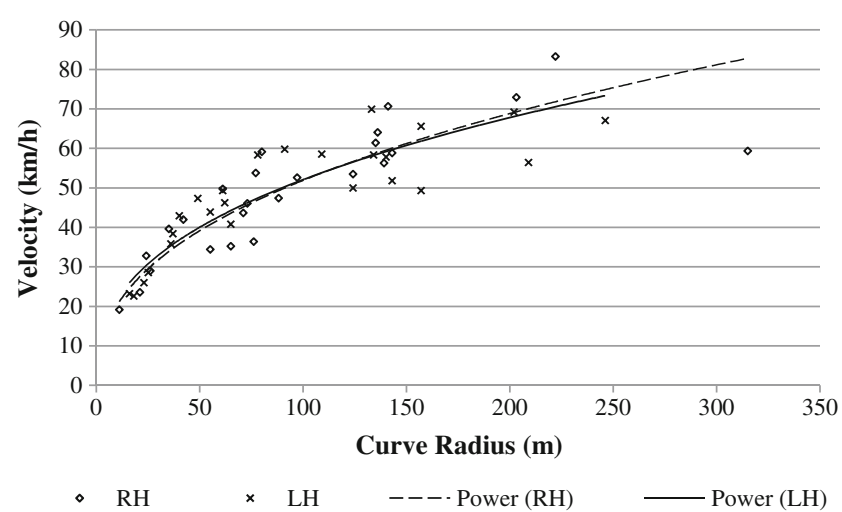

Fig. 6 Velocity Vs curve radius in all routes by experienced rider in Right Hand (RH) and Left Hand ( $\mathrm{LH})$ curves during daylight

\section{Conclusions}

In the present study we introduce a new methodology aiming to investigate motorcyclists' behavior in curved road sections based on global positioning system (GPS) technology. In contrast to the majority of the studies that have been carried so far, where the velocities were recorded using a radar gun installed at a fixed point, usually in the middle of the curves and hence, the researchers have to install multiple radar guns in order to obtain speed data in multiple locations, the new methodology allows the investigation of motorcyclists' behavior in multiple locations since the riding performance data are recorded constantly throughout the trajectory of the rider.

Therefore, the primary scope of the paper is not to draw specific conclusions of the riding patterns observed but rather to demonstrate the feasibility of an alternative methodology in order to study riding behavior at curved road sections. The validation of the proposed methodology was performed by recruiting two motorcyclists, based on demographic, psychometric and experience criteria who rode an instrumented bike in three different two lane rural roads under different driving

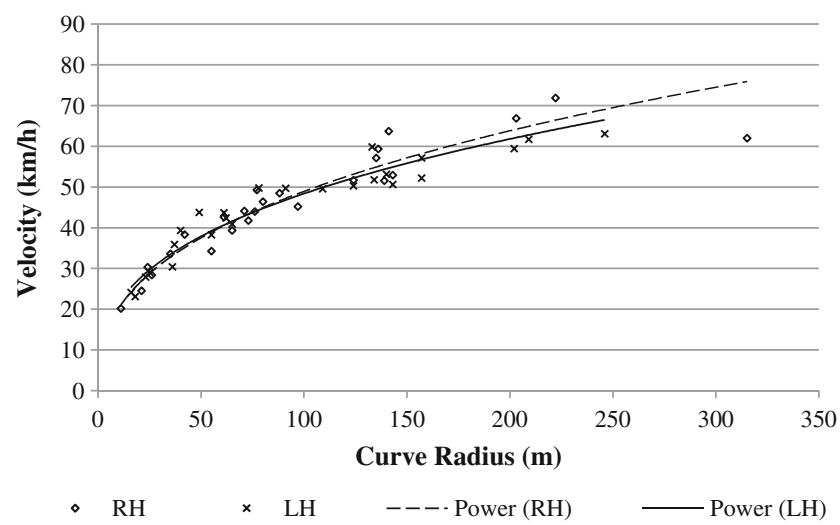

Fig. 7 Velocity Vs curve radius in all routes by inexperienced rider in Right Hand (RH) and Left Hand (LH) curves during nightlight 


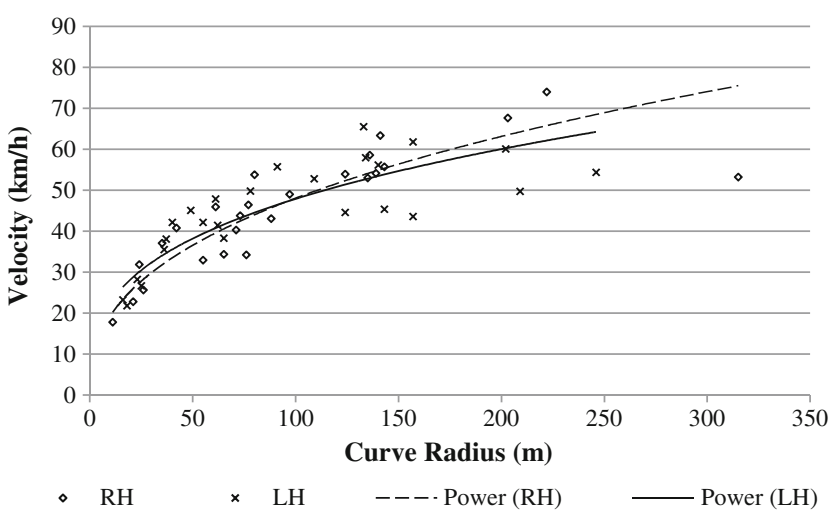

Fig. 8 Velocity Vs curve radius in all routes by experienced rider in Right Hand (RH) and Left Hand (LH) curves during nightlight

conditions (i.e. presence of pillion, different light conditions). The ultimate target was the determination of the optimum regression curve between the curve radius' and the corresponding velocities in a form of a power law of the form $U$ $=\mathrm{ar}^{\mathrm{b}}$, which accomplished with the implementation of the ordinary least square method. The afore-mentioned form was inspired from the fact that the velocity of a body in a uniform circular motion would lead to a behavior $b=0.5$. Hence, the deviation of the exponent from this value would be indicative whether the motion approaches circular motion or not.

Within the limitations of the experiment (studied sites, number of participants, type of motorcycle) the conclusions drawn from the analysis of the recorded data, are presented below:

- Both riders travel with higher speeds in right hand curves with radiuses above $100 \mathrm{~m}$ and independently of the light conditions, than in left hand curves. This conclusion reverses for curves with radiuses below $100 \mathrm{~m}$, phenomenon that should be further investigated in the future.

- The data U,R could be fitted using a power law behavior $U=\mathrm{aR}^{\mathrm{b}}$ and the coefficient could be used as a classification

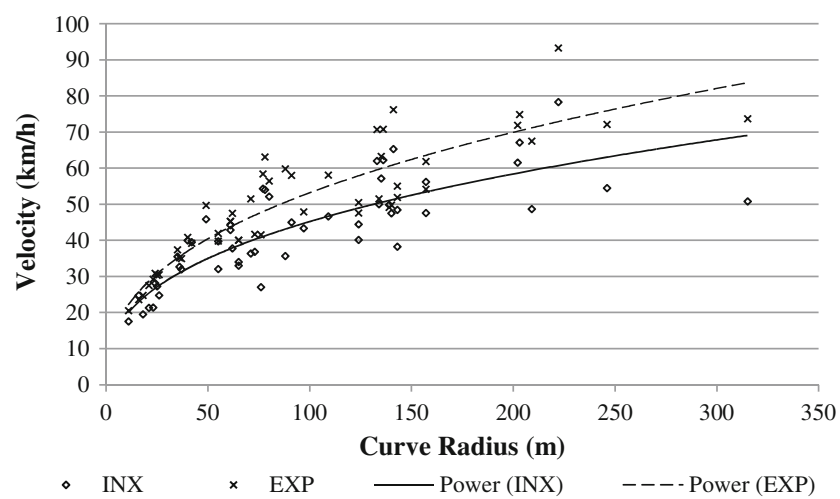

Fig. 9 Velocity Vs curve radius in all routes by experienced (EXP) and inexperienced (INX) rider with the presence of pillion

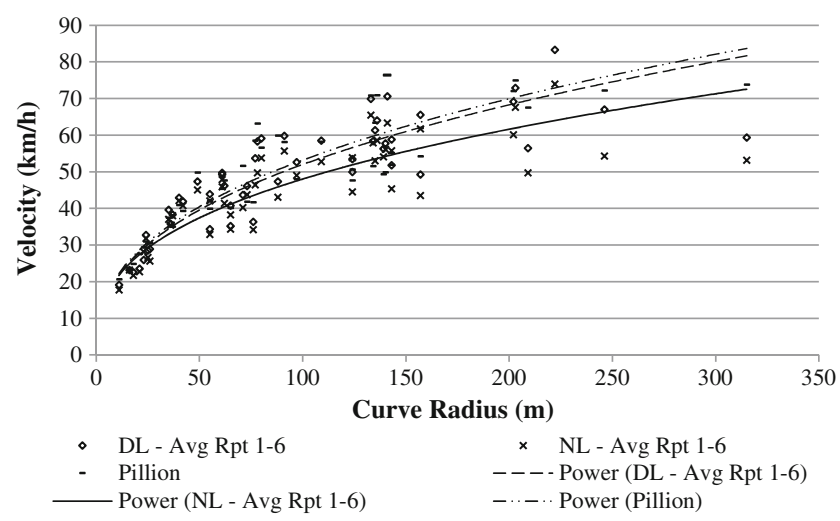

Fig. 10 Velocity Vs curve radius in all routes by experienced rider during daylight (DL), nightlight (NL) and with the presence of pillion (Pillion)

tool of the road curves. A combination of decreased b value and increased a value leads to the conclusion that such curve gathers poor geometric characteristics.

- With regards to the presence of the pillion, the considerably higher mean velocity of the experienced rider in comparison to the corresponding velocity of the inexperienced rider was indisputable. Hence, the experienced rider probably perceives more efficiently the benefit of the increased weight of the system motorcycle - rider-pillion which is accompanied by the increase of the side friction and therefore it permits higher speeds.

The results and conclusions presented above were not based upon the geometrical radius of the curves and thus cannot be used as evaluation criteria of design consistency. Actually the scientific contribution of the present paper should be considered as a first step on which further research should be based on incorporating a larger sample of motorcyclists in order to fine tune the proposed methodology, since there is no similar work examining riding patterns, at least to authors' knowledge, using GPS technology to obtain speed data for motorcycles.

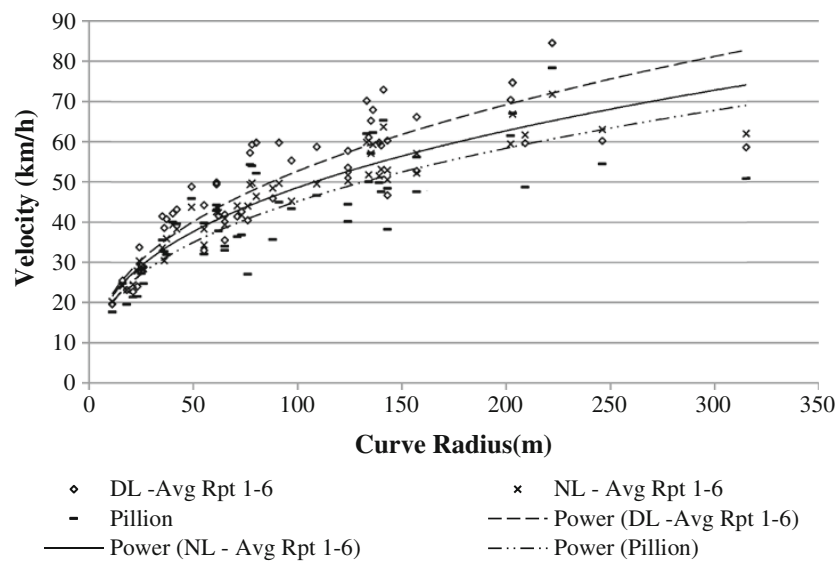

Fig. 11 Velocity Vs curve radius in all routes by inexperienced rider during daylight (DL), nightlight (NL) and with the presence of pillion (Pillion) 


\section{Appendix}

Table 4 shows the trend lines as well as the corresponding errors for the various riding conditions. It has to be noted that the coefficient of determination $\mathrm{R}^{2}$ ranged from 0.745 to 0.973 while initials A-A stand for route Afyssos - Afetai, initials
M-L stand for route Milina - Lafkos, initials N-K stand for route Neohori - Kalamaki, initials INX stand for experienced rider, initials INX stand for inexperienced rider, initials DL stand for Daylight, initials NL stand for Nightlight and finally initials Avg stand for Average.

Table 4 Equations and errors of ordinary least square method

\begin{tabular}{|c|c|c|c|c|c|c|c|c|c|}
\hline \multirow[t]{2}{*}{$\mathrm{s} / \mathrm{n}$} & \multicolumn{6}{|c|}{ Condition } & \multirow[t]{2}{*}{ Trendline $U=\mathrm{aR}^{\mathrm{b}}$} & \multirow[t]{2}{*}{$\pm \delta \mathrm{a}$} & \multirow[t]{2}{*}{$\pm \delta \mathrm{b}$} \\
\hline & $1^{\mathrm{a}}$ & $2^{\mathrm{b}}$ & $3^{\mathrm{c}}$ & $4^{7}$ & $5^{8}$ & $6^{9}$ & & & \\
\hline 1 & A-A & INX & DL & Avg 1-3 & No & Both & $y=8.427 x^{0.367}$ & 1.046 & 0.011 \\
\hline 2 & A-A & INX & DL & Avg 4-6 & No & Both & $y=9.078 \mathrm{x}^{0.338}$ & 1.043 & 0.010 \\
\hline 3 & A-A & EXP & DL & Avg 1-3 & No & Both & $y=8.596 \mathrm{x}^{0.357}$ & 1.044 & 0.010 \\
\hline 4 & A-A & EXP & DL & Avg 4-6 & No & Both & $y=8.281 x^{0.367}$ & 1.046 & 0.011 \\
\hline 5 & A-A & INX & DL & Avg 1-6 & No & Both & $y=8.739 x^{0.353}$ & 1.042 & 0.010 \\
\hline 6 & A-A & EXP & DL & Avg 1-6 & No & Both & $y=8.439 \mathrm{x}^{0.362}$ & 1.044 & 0.010 \\
\hline 7 & A-A & INX & NL & Avg 1-3 & No & Both & $y=8.973 x^{0.354}$ & 1.031 & 0.007 \\
\hline 8 & A-A & INX & NL & Avg 4-6 & No & Both & $y=8.756 \mathrm{x}^{0.362}$ & 1.034 & 0.008 \\
\hline 9 & A-A & EXP & NL & Avg 1-3 & No & Both & $y=9.305 x^{0.314}$ & 1.041 & 0.010 \\
\hline 10 & A-A & EXP & NL & Avg 4-6 & No & Both & $y=9.142 \mathrm{x}^{0.329}$ & 1.043 & 0.010 \\
\hline 11 & A-A & INX & NL & Avg 1-6 & No & Both & $y=8.866 \mathrm{x}^{0.358}$ & 1.030 & 0.007 \\
\hline 12 & A-A & EXP & NL & Avg 1-6 & No & Both & $y=9.220 \mathrm{x}^{0.322}$ & 1.042 & 0.010 \\
\hline 13 & M-L & INX & DL & Avg 1-3 & No & Both & $y=12.29 \mathrm{x}^{0.328}$ & 1.111 & 0.024 \\
\hline 14 & M-L & INX & DL & Avg 4-6 & No & Both & $y=13.50 x^{0.307}$ & 1.097 & 0.021 \\
\hline 15 & M-L & EXP & DL & Avg 1-3 & No & Both & $y=12.67 \mathrm{x}^{0.312}$ & 1.105 & 0.023 \\
\hline 16 & M-L & EXP & DL & Avg 4-6 & No & Both & $y=12.43 x^{0.325}$ & 1.119 & 0.026 \\
\hline 17 & M-L & INX & DL & Avg 1-6 & No & Both & $y=12.88 x^{0.318}$ & 1.102 & 0.022 \\
\hline 18 & M-L & EXP & DL & Avg 1-6 & No & Both & $y=12.55 \mathrm{x}^{0.318}$ & 1.110 & 0.024 \\
\hline 19 & M-L & INX & NL & Avg 1-3 & No & Both & $y=10.06 x^{0.335}$ & 1.078 & 0.017 \\
\hline 20 & M-L & INX & NL & Avg 4-6 & No & Both & $y=12.46 x^{0.297}$ & 1.089 & 0.020 \\
\hline 21 & M-L & EXP & NL & Avg 1-3 & No & Both & $y=12.92 x^{0.288}$ & 1.084 & 0.019 \\
\hline 22 & M-L & EXP & NL & Avg 4-6 & No & Both & $y=12.28 x^{0.326}$ & 1.103 & 0.023 \\
\hline 23 & M-L & INX & NL & Avg 1-6 & No & Both & $y=11.22 x^{0.316}$ & 1.080 & 0.018 \\
\hline 24 & M-L & EXP & NL & Avg 1-6 & No & Both & $y=12.56 x^{0.308}$ & 1.086 & 0.019 \\
\hline 25 & $\mathrm{~N}-\mathrm{K}$ & INX & DL & Avg 1-3 & No & Both & $y=16.01 \mathrm{x}^{0.288}$ & 1.271 & 0.049 \\
\hline 26 & $\mathrm{~N}-\mathrm{K}$ & INX & DL & Avg 4-6 & No & Both & $y=15.03 x^{0.313}$ & 1.268 & 0.049 \\
\hline 27 & $\mathrm{~N}-\mathrm{K}$ & EXP & DL & Avg 1-3 & No & Both & $y=15.38 x^{0.294}$ & 1.310 & 0.056 \\
\hline 28 & $\mathrm{~N}-\mathrm{K}$ & EXP & DL & Avg 4-6 & No & Both & $y=13.06 x^{0.332}$ & 1.343 & 0.061 \\
\hline 29 & $\mathrm{~N}-\mathrm{K}$ & INX & DL & Avg 1-6 & No & Both & $y=15.49 x^{0.301}$ & 1.264 & 0.048 \\
\hline 30 & $\mathrm{~N}-\mathrm{K}$ & EXP & $\mathrm{DL}$ & Avg 1-6 & No & Both & $y=14.17 \mathrm{x}^{0.313}$ & 1.324 & 0.058 \\
\hline 31 & $\mathrm{~N}-\mathrm{K}$ & INX & $\mathrm{NL}$ & Avg 1-3 & No & Both & $y=14.81 x^{0.281}$ & 1.322 & 0.057 \\
\hline 32 & $\mathrm{~N}-\mathrm{K}$ & INX & NL & Avg 4-6 & No & Both & $y=13.32 \mathrm{x}^{0.303}$ & 1.213 & 0.040 \\
\hline 33 & $\mathrm{~N}-\mathrm{K}$ & EXP & NL & Avg 1-3 & No & Both & $y=13.05 x^{0.305}$ & 1.430 & 0.074 \\
\hline 34 & $\mathrm{~N}-\mathrm{K}$ & EXP & NL & Avg 4-6 & No & Both & $y=13.32 x^{0.305}$ & 1.457 & 0.078 \\
\hline 35 & $\mathrm{~N}-\mathrm{K}$ & INX & NL & Avg 1-6 & No & Both & $y=14.04 x^{0.292}$ & 1.264 & 0.048 \\
\hline 36 & $\mathrm{~N}-\mathrm{K}$ & EXP & NL & Avg 1-6 & No & Both & $y=13.18 \mathrm{x}^{0.305}$ & 1.440 & 0.075 \\
\hline 37 & All & INX & DL & Avg 1-3 & No & Both & $y=8.636 x^{0.393}$ & 1.045 & 0.010 \\
\hline 38 & All & INX & DL & Avg 4-6 & No & Both & $y=8.733 x^{0.390}$ & 1.056 & 0.012 \\
\hline
\end{tabular}


Table 4 (continued)

\begin{tabular}{|c|c|c|c|c|c|c|c|c|c|}
\hline \multirow[t]{2}{*}{$\mathrm{s} / \mathrm{n}$} & \multicolumn{6}{|c|}{ Condition } & \multirow[t]{2}{*}{ Trendline $U=\mathrm{aR}^{\mathrm{b}}$} & \multirow[t]{2}{*}{$\pm \delta \mathrm{a}$} & \multirow[t]{2}{*}{$\pm \delta \mathrm{b}$} \\
\hline & $1^{\mathrm{a}}$ & $2^{\mathrm{b}}$ & $3^{\mathrm{c}}$ & $4^{7}$ & $5^{8}$ & $6^{9}$ & & & \\
\hline 39 & All & EXP & DL & Avg 1-3 & No & Both & $y=8.684 x^{0.386}$ & 1.044 & 0.010 \\
\hline 40 & All & EXP & DL & Avg 4-6 & No & Both & $y=8.344 \mathrm{x}^{0.399}$ & 1.049 & 0.011 \\
\hline 41 & All & INX & DL & Avg 1-6 & No & Both & $y=8.680 x^{0.392}$ & 1.050 & 0.011 \\
\hline 42 & All & EXP & DL & Avg 1-6 & No & Both & $y=8.512 \mathrm{x}^{0.393}$ & 1.046 & 0.010 \\
\hline 43 & All & INX & NL & Avg 1-3 & No & Both & $y=8.775 \mathrm{x}^{0.369}$ & 1.026 & 0.006 \\
\hline 44 & All & INX & NL & Avg 4-6 & No & Both & $y=9.136 \mathrm{x}^{0.365}$ & 1.027 & 0.006 \\
\hline 45 & All & EXP & NL & Avg 1-3 & No & Both & $y=9.087 \mathrm{x}^{0.353}$ & 1.046 & 0.010 \\
\hline 46 & All & EXP & NL & Avg 4-6 & No & Both & $y=9.224 x^{0.365}$ & 1.051 & 0.011 \\
\hline 47 & All & INX & NL & Avg 1-6 & No & Both & $y=8.962 \mathrm{x}^{0.367}$ & 1.025 & 0.006 \\
\hline 48 & All & EXP & NL & Avg 1-6 & No & Both & $y=9.154 x^{0.359}$ & 1.048 & 0.011 \\
\hline 49 & A-A & INX & DL & - & Yes & Both & $y=8.598 x^{0.321}$ & 1.053 & 0.012 \\
\hline 50 & A-A & EXP & DL & - & Yes & Both & $y=8.616 x^{0.382}$ & 1.044 & 0.010 \\
\hline 51 & M-L & INX & DL & - & Yes & Both & $y=13.21 \mathrm{x}^{0.271}$ & 1.136 & 0.029 \\
\hline 52 & M-L & EXP & DL & - & Yes & Both & $y=13.37 \mathrm{x}^{0.286}$ & 1.150 & 0.032 \\
\hline 53 & $\mathrm{~N}-\mathrm{K}$ & INX & DL & - & Yes & Both & $y=16.49 x^{0.268}$ & 1.347 & 0.061 \\
\hline 54 & $\mathrm{~N}-\mathrm{K}$ & EXP & DL & - & Yes & Both & $y=15.26 x^{0.310}$ & 1.449 & 0.077 \\
\hline 55 & All & INX & DL & - & Yes & Both & $y=8.241 \mathrm{x}^{0.369}$ & 1.057 & 0.013 \\
\hline 56 & All & EXP & DL & - & Yes & Both & $y=8.644 x^{0.394}$ & 1.042 & 0.009 \\
\hline 57 & All & INX & DL & Avg 1-6 & No & RH & $y=7.798 \mathrm{x}^{0.416}$ & 1.108 & 0.023 \\
\hline 58 & All & INX & DL & Avg 1-6 & No & LH & $y=9.656 x^{0.367}$ & 1.094 & 0.021 \\
\hline 59 & All & EXP & DL & Avg 1-6 & No & RH & $y=7.995 \mathrm{x}^{0.406}$ & 1.098 & 0.021 \\
\hline 60 & All & EXP & DL & Avg 1-6 & No & LH & $y=9.054 x^{0.379}$ & 1.094 & 0.021 \\
\hline 61 & All & INX & NL & Avg 1-6 & No & RH & $y=8.430 x^{0.382}$ & 1.053 & 0.012 \\
\hline 62 & All & INX & NL & Avg 1-6 & No & $\mathrm{LH}$ & $y=9.528 x^{0.352}$ & 1.049 & 0.011 \\
\hline 63 & All & EXP & NL & Avg 1-6 & No & $\mathrm{RH}$ & $y=7.852 x^{0.393}$ & 1.1 & 0.021 \\
\hline 64 & All & EXP & NL & Avg 1-6 & No & LH & $y=10.650 x^{0.326}$ & 1.1 & 0.021 \\
\hline
\end{tabular}

${ }^{\mathrm{a}} 1=$ Route

${ }^{\mathrm{b}} 2=$ Rider

${ }^{\mathrm{c}} 3=$ Light conditions

${ }^{4} 4=$ Repetitions

${ }^{5} 5=$ Presence of pillion

${ }^{6} 6=$ Curve direction

Open Access This article is distributed under the terms of the Creative Commons Attribution License which permits any use, distribution, and reproduction in any medium, provided the original author(s) and the source are credited.

\section{References}

1. Islam NM, Seneviratne PN (1994) Evaluation of design consistency of two-lane rural highways. ITE J 64:28-31

2. Voigt AP, Krammes RA (1998) "An operational and safety evaluation of alternative horizontal curve design approaches on rural twolane highways," in International Symposium on Highway Geometric Design Practices, Boston, Massachusetts
3. Wooldridge MD, Fitzpatrick K, Harwood DW, Potts IB, Elefteriadou L, Torbic DJ (2003) "NCHRP Report 502: Geometric design consistency on high-speed rural two-lane roadways," National Cooperative Highway Research Program. Transportation Research Program, Washington DC

4. Tate F, Turner S (2007) "Road geometry and drivers speed choice", Road and Transport Research 16(4)

5. Mazzella A, Pinna F, Piras C (2010) "Geostatical approach for operating speed modelling on Italian roads," Valencia

6. Wong YD, Nicholson A (1992) Driver behaviour at horizontal curves: risk compensation and the margin of safety. Accid Anal Prev 24(4):425-436

7. Transportation Research Board, Modeling operating speed, Washington, DC: Transportation Research Circular, TRB, 2011

8. Perco P (2008) Comparison between powered two wheeler and passenger car free-flow speeds in urban areas. Transp Res Rec 2074:77-84 
9. Faezi SF, Hamid H, Davoodi SR (2011) Predicting speed model of horizontal curves on exclusive motorcycle lane. Aust J Basic Appl Sci 5(5):590-598, no. ISI Thomson

10. Fildes NB, Leening CA, Corrigan MJ (1989) 'Speed perception: Drivers' judgements of safety and speed on rural straight and curved roads and for different following distances", Report no. CR60, Dept. of Transport, Federal Office of Road Safety, Victoria 3174, Australia, Canberra

11. Othman S, Thomson R, Lanner G (2010) Are driving and overtaking on right curves more dangerous than on left curves? Assoc Adv Automot Med 54:253-264

12. Koorey G, Page S, Stewart P, Gu J, Ellis A, Henderson R, Cenek P (2002) "Curve advisory speeds in New Zealand.", Transfund New Zealand Research Report no. 226, Wellington

13. Bennett CR (1994) A speed prediction model for rural two-lane highways. Ph. D Dissertation. Department of Civil Engineering The University of Auckland, Auckland

14. C. FESTA, Deliverable 2.3 (D2.3), Primer on experimental procedures, Grant aggrement number 214853: Field opErational teSt supporT Action (FESTA), 2008
15. Yannis G, Golias J, Papadimitriou E, Spyropoulou I (2005) "Accident risk analysis of passenger car drivers and two-wheeler riders in Greece," in 3rd Hellenic Conference of Road Safety, Patra, Greece

16. Joshi S, Bellet T, Banet A, Rößger L, Turetschek C, Risser R, Golias J, Yannis G, Spyropoulou I, Carvalhais J, Leden L, Vasek J, Delhaye A, Roebroeck H, Underwood G, Humphrey K (2010) "Understanding risk taking behaviour within the context of PTW riders: a report on rider diversity with regard to attitudes, perceptions and behavioural choices.", 2BESAFE, Deliverable n. 7, EU

17. Pratico FG, Giunta M (2010) "Operational and safety effects of twolane roads alignment," in Proceedings of 4th International Symposium on Highway Geometric Design, Valencia, Spain

18. Castro M, Sanchez JF, Ardila N, Melo J (2010) "Speed models for highway consistency analysis. A colombian case study", in 4th International Symposium on Highway Geometric Design, Valencia

19. Abdul-Mawjoud A, Sofia G (2008) "Development of models for predicting speed on horizontal curves for two-lane rural highways," vol. 33 , no. $2 \mathrm{~B}$ 